\title{
Characterization of Trypanosoma cruzi Strains Isolated from Chronic Chagasic Patients, Triatomines and Opossums Naturally Infected from the State of Rio Grande do Sul, Brazil
}

\author{
Cloé Duarte Fernandes, Silvane Maria Fonseca Murta*, Isabela Penna \\ Cerávolo*, Luciano Percival Krug, Pedro G Vidigal*, Mario Steindel***, \\ Nanci Nardi**, Alvaro José Romanha*/+
}

Instituto de Pesquisas Biológicas - SSMA/RS, Rua Domingos Crescêncio 132, 90650-090 Porto Alegre, RS, Brasil *Laboratório de Parasitologia Celular e Molecular, Centro de Pesquisas René Rachou-FIOCRUZ, Av. Augusto de Lima 1715, 30190-002 Belo Horizonte, MG, Brasil ** Departamento de Genética, Universidade Federal do Rio Grande do Sul, Av. Bento Gonçalves 9500, Campus do Vale, 91540-000 Porto Alegre, RS, Brasil *** Departamento de Microbiologia e Parasitologia, Universidade Federal de Santa Catarina,

Florianópolis, SC, Brasil

Thirty-five Trypanosoma cruzi strains were isolated from chronic chagasic patients, triatomines and opossums from different municipalities of the State of Rio Grande do Sul. Parasites were characterized by means of mice infectivity, enzyme electrophoresis and randomly amplified polymorphic DNA (RAPD) analysis. Twenty-nine strains were isolated from chagasic patients, 4 from triatomines ( 2 from Triatoma infestans and 2 from Panstrongylus megistus) and 2 from opossums Didelphis albiventris. Thirty-three T. cruzi strains were of low and 2 strains of high virulence in mice. Both virulent strains were isolated from P. megistus. Isoenzyme analysis of the strains showed 3 different zymodemes. Eleven strains isolated from chagasic patients and 2 from $\mathrm{D}$. albiventris were Z2. Eighteen strains from patients and 2 from $\mathrm{T}$. infestans were $Z B$ and $2 \mathrm{~T}$. cruzi strains isolated from $\mathrm{P}$. megistus were Z1. RAPD profiles obtained with 4 random primers showed a high genetic heterogeneity of the T. cruzi strains. Zymodeme 2 and $Z B$ strains were the more polymorphic. A band sharing analysis of the RAPD profiles of Z2 and ZB strains using 3 primers, showed a very low percentage of shared bands, 20\% among $13 \mathrm{ZB}$ strains and $14 \%$ among $13 \mathrm{Z2}$ strains. According to the isoenzyme results, 3 T. cruzi populations were present in State of Rio Grande do Sul. Zymodeme 2 and ZB strains were found infecting man (domiciliar transmission cycle) whereas $Z 1$ strains were found infecting the sylvatic vector $\mathrm{P}$. megistus.

Key words: Chagas' disease - Trypanosoma cruzi - randomly amplified polymorphic DNA - isoenzyme characterization - epidemiology

Trypanosoma cruzi, the ethiological agent of Chagas' disease is a digenetic flagellate protozoan transmitted to the mammal host by means of infected feces or urine of triatomine bugs (WHO 1991). In Brazil the endemic area of Chagas' disease comprises more than 3 million $\mathrm{km}^{2}$, and it is estimated that around 5 million people are infected by $T$. cruzi (Dias 1987). Intraspecific variations in T. cruzi have been demonstrated at the biological, immunological, biochemical and genetic levels (Brener 1977, Miles et al. 1977, Morel et al. 1980, Andrade 1985, Tibayrenc \& Ayala 1988, Steindel et al. 1993). Enzyme electrophoresis studies have demonstrated that distinct $T$. cruzi populations

${ }^{+}$Corresponding author. Fax: +55-31-295.3115

Received 1 November 1996

Accepted 10 March 1997 (zymodemes) are circulating in the domestic and sylvatic transmission cycles (Miles et al. 1977, 1978). Therefore, isoenzyme provides a good marker in epidemiological studies of Chagas' disease. Recently, randomly amplified polymorphic DNA (RAPD), has been used in studies of genetic diversity of trypanosomes (Dirie et al. 1993, Steindel et al. 1993, Tibayrenc et al. 1993). This technique has been widely applied to the study of parasite populations because of its simplicity, the lack of requirement of DNA sequence information for primer design and its great power in mapping genomes (Steindel et al. 1993). Studies of genetic variability using molecular markers such as kDNA (schizodemes) (Morel et al. 1980), DNA fingerprinting using multilocal probes (Macedo et al. 1992) and RAPD defined highly variable groups of $T$. cruzi. Recently, 2 independent nuclear markers, ribosomal RNA and mini-exon genes, allowed 
the division of $T$. cruzi strains into 2 groups (Souto et al. 1996).

In the Southern region of Brazil, the State of Rio Grande do Sul is the most important endemic area of human Chagas' disease with infection rates varying from $17.6 \%$ to $19.6 \%$ in the south region of the State (Baruffa \& Alcântara Filho 1977, 1985). Investigation of the triatomine fauna showed that at least, 7 triatomine species were present. Triatoma infestans was the only domestic vector species found (Coutinho et al. 1952). According to the 1980 population census, it is estimated that around 700 thousand people are infected by $T$. cruzi in Rio Grande do Sul (Baruffa 1987). Although with such a high prevalence, a few number of $T$. cruzi strains have been studied and little is known about the parasite populations that circulate in the different transmission cycles there. In the present work, we characterized by means of virulence in mice, isoenzyme electrophoresis and RAPD analysis, 35 T. cruzi strains isolated from chronic chagasic patients, triatomines and opossums from Rio Grande do Sul.

\section{MATERIALS AND METHODS}

Parasite isolation - Authoctonous chronic chagasic patients from Rio Grande do Sul with positive immunofluorescence and/or hemagglutination antibody test, were submitted to xenodiagnosis with 30 fourth instar nymphs of $T$. infestans or hemoculture in liver infusion tryptose (LIT) medium for parasite isolation. Adults of T. infestans captured inside houses and Panstrongylus megistus collected in the peridomiciliar environment by personnel of the National Foundation of Health (FNS), were examined by fresh feces smears and the positive insects were submitted to a xenoculture in LIT for parasite isolation (Bronfen et al. 1989). Opossums Didelphis albiventris captured in peridomiciliar areas of Porto Alegre city by the Vector Control Division of the Health and Environment Secretary, were submitted to xenodiagnosis for searching and isolation of T. cruzi. The parasites isolated were maintained by weekly passages in LIT medium at $28^{\circ} \mathrm{C}$ or cryopreserved in liquid nitrogen.

Parasitemia - Groups of 5 male albino mice weighting 15 to $18 \mathrm{~g}$ were inoculated with $5 \times 10^{3}$ blood trypomastigotes by the intraperitoneal route with different $T$. cruzi strains. The parasitemia was followed every 2 days from the 6th to the 50th day of infection by fresh blood smears and the number of parasites estimated as described by Brener (1962). Curves were plotted using the mean parasitemia of 5 mice for each day of study. Mortality rate was expressed as percentage of accumulated deaths at the 60 day of inoculation. The virulence of the strains was determined according to pre- patent period, parasitemia level and mortality rate.

Isoenzyme profile - Parasites were grown in flasks containing $30 \mathrm{ml}$ of LIT medium at $28^{\circ} \mathrm{C}$, harvested in the exponential phase and washed 3 times by centrifugation, $2,000 \mathrm{x} \mathrm{g}, 4^{\circ} \mathrm{C}, 10 \mathrm{~min}$ in KRT (Krebs Ringer Tris, pH 7.4) buffer and the parasite pellet was stored at $-70^{\circ} \mathrm{C}$ until use. The pellet was thawed at room temperature and submitted to osmotic lysis in an enzyme stabilizer ( 2.0 $\mathrm{mM}$ dithiothreitol, $2.0 \mathrm{mM} \varepsilon$-amino caproic acid, $2.0 \mathrm{mM} \mathrm{Na}_{2}$ EDTA, pH 7.4) at $4^{\circ} \mathrm{C}$ at a volume ratio $1: 1$. The lysate was centrifuged at $15,000 \mathrm{x} \mathrm{g}$ for $1 \mathrm{hr}$ at $4^{\circ} \mathrm{C}$, and the supernatant (enzymatic extract) was collected and stored as $15 \mu \mathrm{l}$ beads in liquid nitrogen. The following 6 enzymes were analyzed: alanine aminotransferase (ALAT) [E.C.2.6.1.2]; aspartate aminotransferase (ASAT) [E.C.2.6.1.1]; glucose phosphate isomerase (GPI) [E.C.5.3.1.9]; phosphoglucomutase (PGM) [E.C.2.7.5.1]; glucose-6-phosphate dehydrogenase (G6PD) [E.C.1.1.1.49] and malic enzyme (ME) [E.C.1.1.1.40]. Electrophoretic separation and enzyme staining were done as described by Carneiro et al. (1990). Standard T. cruzi zymodemes Z1, Z2, $\mathrm{ZB}$ and $\mathrm{ZC}$ were used as reference.

DNA preparation -The isolation, amplification and electrophoresis of the parasite DNA was essentially the same as described by Steindel et al. (1993). Briefly, parasite pellet was resuspended in $50 \mathrm{mM}$ Tris-HCl/ $50 \mathrm{mM}$ EDTA/ $100 \mathrm{mM} \mathrm{NaCl} /$ $0.5 \%$ SDS, $\mathrm{pH} 8.0$ (extraction buffer) and incubated with $20 \mu \mathrm{g} \mathrm{ml}^{-1}$ proteinase $\mathrm{K}$ for $2 \mathrm{hr}$ at $45^{\circ} \mathrm{C}$. Following phenol/chloroform extraction and ethanol precipitation the DNA was resuspended in 10 $\mathrm{mM}$ Tris-HCl/ $1 \mathrm{mM}$ EDTA pH 8.0 (TE buffer) and digested with $1 \mathrm{U} \mathrm{ml}^{-1}$ RNAse (Sigma Chemical Co., St. Louis, Mo, USA) for $2 \mathrm{hr}$ at $37^{\circ} \mathrm{C}$. Following a new round of phenol/chloroform extraction and ethanol precipitation the DNA was resuspended in TE $\mathrm{pH} 8.0$ and its concentration determined by comparison against known standard following agarose gel electrophoresis stained with ethidium bromide.

$R A P D$ - The amplification reaction was done in a termocycler (MJR Research Inc. - PTC 100), in a final volume of $10 \mu \mathrm{l}$ containing 0.8 units of Taq DNA polymerase (CENBIOT, RS, Brasil), 200 $\mathrm{mM}$ of each dNTP, $1.5 \mathrm{mM} \mathrm{MgCl}_{2}, 50 \mathrm{mM} \mathrm{KCl}$, $10 \mathrm{mM}$ Tris-HCl, pH 8.5 together with $6.4 \mathrm{pmol}$ of each primer and $1.0 \mathrm{ng}$ of template DNA.

The primers 3303 (5'- TCACGATGCA -3'), 3307 (5'- AGTGCTACGC -3'), $\lambda \mathrm{gt} 11 \mathrm{~F}$ (5'- GGTG GCGACGACTCCTGGAGCCCG -3') and $\lambda$ gt $11 \mathrm{R}$ (5'-TTGACACCAGACCAACTGGTAATG -3'), were arbitrarily selected from the laboratory stocks. The reaction mixture was overlaid with $20 \mu \mathrm{l}$ of 
mineral oil and, following an initial denaturation at $95^{\circ} \mathrm{C}$ for $5 \mathrm{~min}$, it was subjected to 2 cycles through the following temperature profile: $30^{\circ} \mathrm{C}$ for $2 \mathrm{~min}$ for annealing, $72^{\circ} \mathrm{C}$ for $1 \mathrm{~min}$ for extension and $30 \mathrm{sec}$ at $95^{\circ} \mathrm{C}$ for denaturation followed by 33 cycles where the annealing temperature was altered to $40^{\circ} \mathrm{C}$. In the final cycle the extension step was for $5 \mathrm{~min}$. After amplification, $3 \mu \mathrm{l}$ of each reaction was mixed with $0.6 \mu$ of $6 x$ DNA sample buffer $(0.25 \%$ bromophenol blue, $0.25 \%$ xylene cyanol, $30 \%$ glycerol) and subjected to electrophoresis through a $4 \%$ nondenaturating polyacrylamide gel. Gels were fixed with $10 \%$ ethanol/ $0.5 \%$ acetic acid for $20 \mathrm{~min}$ and DNA bands revealed by staining with $0.2 \%$ silver nitrate for $30 \mathrm{~min}$ and reduction with $0.75 \mathrm{M} \mathrm{NaOH} /$ $0.1 \mathrm{M}$ formaldehyde for $10 \mathrm{~min}$ as described by Santos et al. (1993). The gels were analyzed by means of band sharing between all possible pairs and the percentage of common bands was determined.

\section{RESULTS}

T. cruzi isolation - From August 1992 to July 1993, xenodiagnosis and/or hemoculture were performed in 236 chronic chagasic patients from 42 municipalities of Rio Grande do Sul (Fig. 1). From the 29 T. cruzi strains isolated from chagasic patients, 18 were obtained by hemoculture an 11 by xenodiagnosis. Three hundred and forty three triatomines (231 T. infestans and 112 P. megistus) and 11 opossums were captured and searched for T. cruzi. Ten T. infestans (4.3\%), 4 P. megistus (3.6\%) and 2 opossums (18.2\%) were found infected by $T$. cruzi. Only 2 strains from T. infestans and 2 from P. megistus were isolated by xenoculture. In addition, 2 strains were isolated by xenodiagnosis from the infected opossums $(D$. albiventris), captured in the peridomiciliar environment at Porto Alegre city (Table I).

Parasitemia profile - The 35 T. cruzi strains isolated produced patent parasitemia in experimentally inoculated albino mice and showed two distinct parasitemia profiles (Fig. 2). Two strains (RS11and RS21) isolated from the vector P. megistus were of high virulence for mice presenting a short prepatent period ranging from 6 to 8 days, displaying a rapid raising parasitemia reaching $13.1 \times 10^{3}$ parasites/ $5 \mathrm{~mm}^{3}$ of blood and causing $100 \%$ mortality in 16 days. The remaining 33 strains were all of low virulence for mice with prepatent period of 12 to 18 days, and a peak of parasitemia of 900 parasites/ $5 \mathrm{~mm}^{3}$ of blood around the 28th to 32nd day of infection and mortality rate varying from 0 to $10 \%$ at the 60th day of infection.

Isoenzyme profiles - Analysis of 6 enzymes of 35 T. cruzi strains from Rio Grande do Sul revealed

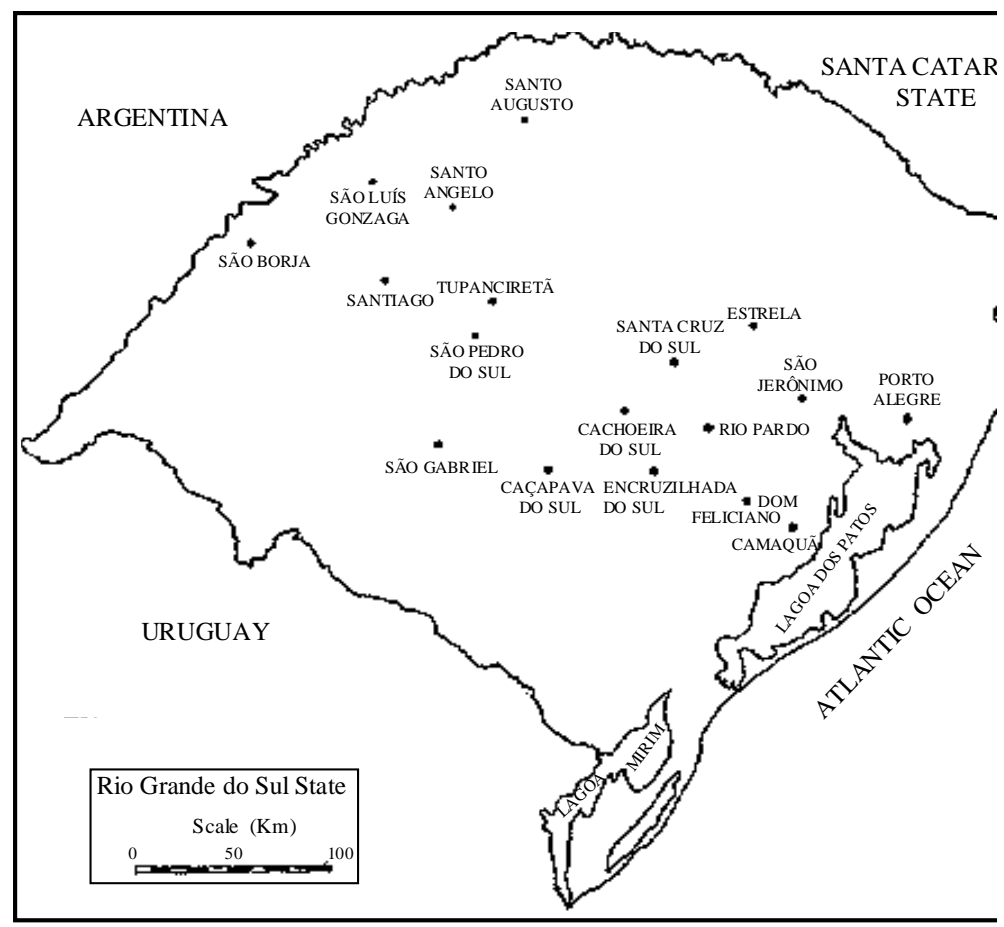

Fig. 1: map of the State of Rio Grande do Sul showing the location of municipalities where Trypanosoma cruzi strains were obtained. 
TABLE I

Host, isolation methods and origin of Trypanosoma cruzi strains from the State of Rio Grande do Sul

\begin{tabular}{llll}
\hline Strains & \multicolumn{1}{c}{ Host } & Isolation/method & Origin \\
\hline RS2 & Man & Hemoculture & Encruzilhada do Sul \\
RS8, RS12, RS13 & Man & Xenodiagnosis & Encruzilhada do Sul \\
RS1, RS23 & Man & Hemoculture & São Jerônimo \\
RS4, RS17 & Man & Hemoculture & Caçapava do Sul \\
RS5, RS20, RS25, RS35 & Man & Hemoculture & Santo Angelo \\
RS6, RS24 & Man & Hemoculture & Rio Pardo \\
RS26 & Man & Xenodiagnosis & Rio Pardo \\
RS7, RS27 & Man & Xenodiagnosis & São Gabriel \\
RS16 & Man & Hemoculture & São Gabriel \\
RS14 & Man & Xenodiagnosis & São Pedro do Sul \\
RS18 & Man & Hemoculture & Estrela \\
RS15 & Man & Hemoculture & Santiago \\
RS19 & Man & Hemoculture & Santo Augusto \\
RS22 & Man & Xenodiagnosis & São Luiz \\
RS28 & Man & Hemoculture & São Borja \\
RS33 & Man & Hemoculture & Santa Cruz do Sul \\
RS36 & Man & Hemoculture & Tupanciretã \\
RS30 & Man & Camaquã \\
RS29 & Man & Xenodiagnosis & Porto Alegre \\
RS31 & Man & Xenoculture & Cachoeira do Sul \\
RS32 & Triatoma infestans & Xenoculture & Cachoeira do Sul \\
RS34 & Triatoma infestans & Democulture & Pom Feliciano \\
RS11, RS21 & Panstrongylus megistus & Xeno Alegre \\
RS9, RS10 & Didelphis albiventris & xenodiagnosis & Porto Alegre \\
\hline & & &
\end{tabular}

3 major zymodemes Z1, Z2 and ZB (Fig. 3, Table II). In all zymodemes minor enzymatic variations were present. From the 29 strains isolated from chronic chagasic patients 11 were zymodeme 2 and 18 zymodeme B. Eight of the Z2 strains, represented by RS 5 strain in Fig. 3, displayed a double instead of a single band in the ASAT enzyme, and were called Z2a (Table II). Another Z2 strain (RS 7) presented an ASAT profile identical to the zymodeme $\mathrm{C}$ and was called Z2b. 2 strains from man (RS 4 and RS 36) and two from D. albiventris (RS 9 and RS 10) presented a typical zymodeme Z2. Sixteen strains from chagasic patients and 2 from $T$. infestans presented a typical zymodeme ZB. The ZB strains RS 25 and RS 33 presented a faster migration on the GPI's triplet bands. Additionally, RS 33 presented double band on ASAT and was called ZBa whereas, RS 25 presented a single band and was called ZBb. The strains RS 11 and RS 21, isolated from $P$. megistus, were identical to the reference $\mathrm{Z} 1$ strain in 5 out of 6 enzymes. They differed on ALAT enzyme and were called Z1a.

RAPD profiles - The RAPD profiles obtained with primer 3303 of 2 T. cruzi strains representative of each zymodeme found in Rio Grande do Sul together with Z1, Z2 and ZB reference zymodemes showed that the major groups defined by RAPD

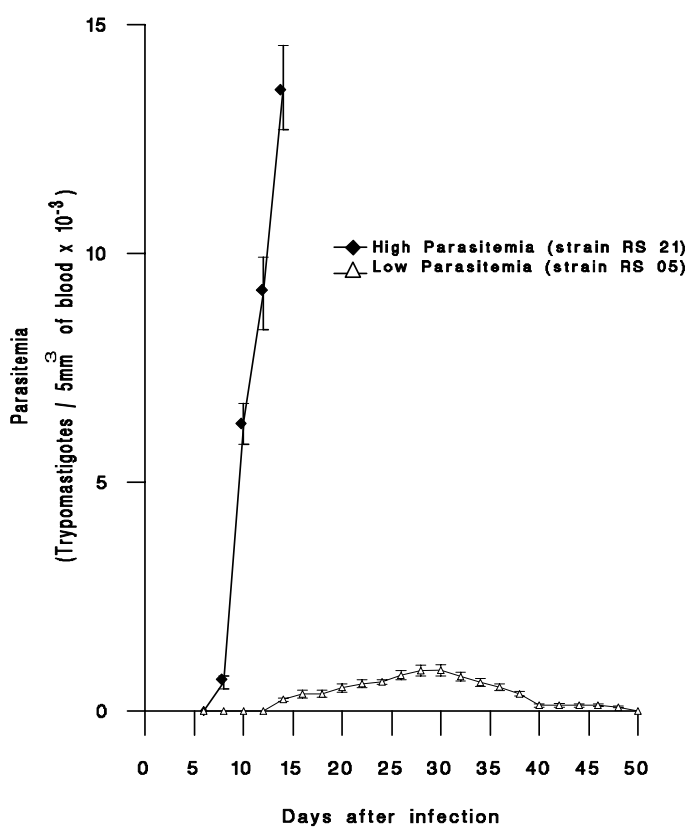

Fig. 2: representative parasitemia curves from Trypanosoma cruzi strains from the State of Rio Grande do Sul in albino mice inoculated intraperitoneally with $5 \times 10^{3}$ blood trypomastigotes. 
ASAT

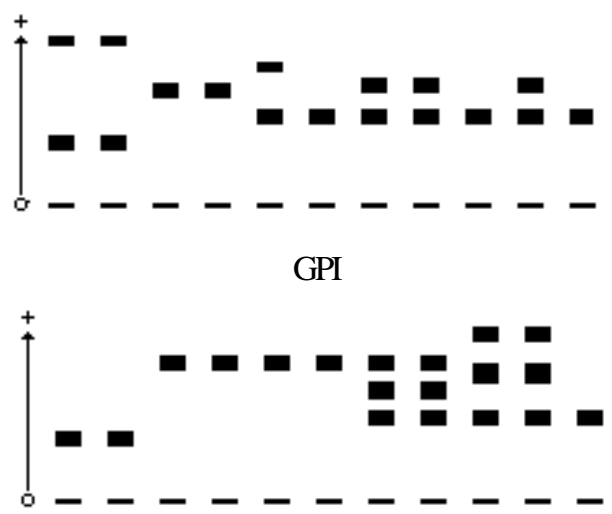

G6PD

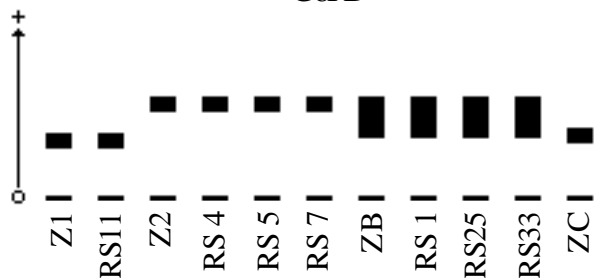

ALAT

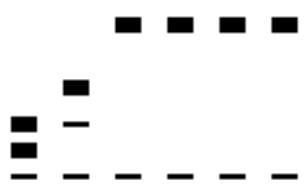

PGM

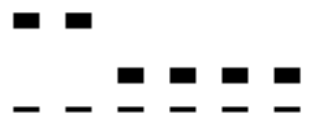

ME

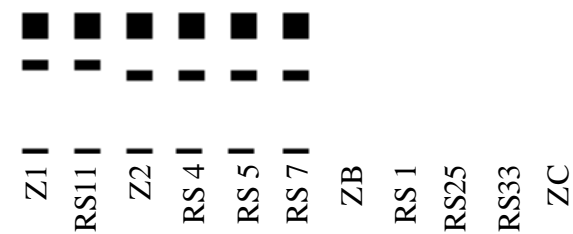

Fig. 3: diagrammatic representation of the isoenzymatic profiles of six enzymes from Trypanosoma cruzi strains from the State of Rio Grande do Sul. For enzyme and strain abbreviations see Materials and Methods and Table II.

TABLE II

Hosts and zymodemes of Trypanosoma cruzi strains from the State of Rio Grande do Sul

\begin{tabular}{|c|c|c|c|}
\hline Strains & Host & Zymodeme & Variant enzymes \\
\hline RS11, RS21 & Panstrongylus megistus & Z1a (02) & ALAT \\
\hline RS9, RS10 & Didelphis albiventris & $\mathrm{Z} 2(02)$ & \\
\hline RS4, RS36 & Man & $\mathrm{Z} 2(02)$ & \\
\hline RS5, RS6, RS26, RS27, RS28, & & & \\
\hline RS29, RS30, RS31 & Man & Z2a (08) & ASAT \\
\hline RS7 & Man & $\mathrm{Z} 2 \mathrm{~b}(01)$ & ASAT \\
\hline $\begin{array}{l}\text { RS1, RS2, RS8, RS12, RS13, } \\
\text { RS14, RS15, RS16, RS17, } \\
\text { RS18, RS19, RS20, RS22, }\end{array}$ & & & \\
\hline RS23, RS24, RS35 & Man & ZB (16) & \\
\hline RS33 & Man & $\mathrm{ZBa}(01)$ & GPI \\
\hline RS25 & Man & $\mathrm{ZBb}(01)$ & ASAT and GPI \\
\hline RS32, RS34 & Triatoma infestans & $\mathrm{ZB}(02)$ & \\
\hline
\end{tabular}

In parenthesis the number of strains with that zymodeme

coincide with the same groups defined by isoenzyme (Fig. 4). A comparative study of RAPD bands of the $2 \mathrm{Z} 1$ strains obtained with 3307 and $\lambda \mathrm{gt} 11 \mathrm{R}$ primers shows that from the 39 bands considered, $74 \%$ were present in both strains (data not shown). In contrast with the homogeneity of the $\mathrm{Z} 1$ strains, the Z2 and ZB T. cruzi strains presented highly polymorphic RAPD profiles with all primers used. Figs 5 and 6 illustrate the RAPD profiles of Z2 and ZB strains with primers 3307 and $\lambda$ gt $11 \mathrm{R}$ respectively. A band sharing analysis using only primer $\lambda \mathrm{gt} 11 \mathrm{~F}$ shows that the percentage of bands shared between 13 ZB strains was of 10/23 (43.4\%) and of $7 / 21(33.3 \%)$ between $13 \mathrm{Z} 2$ strains. However, when 


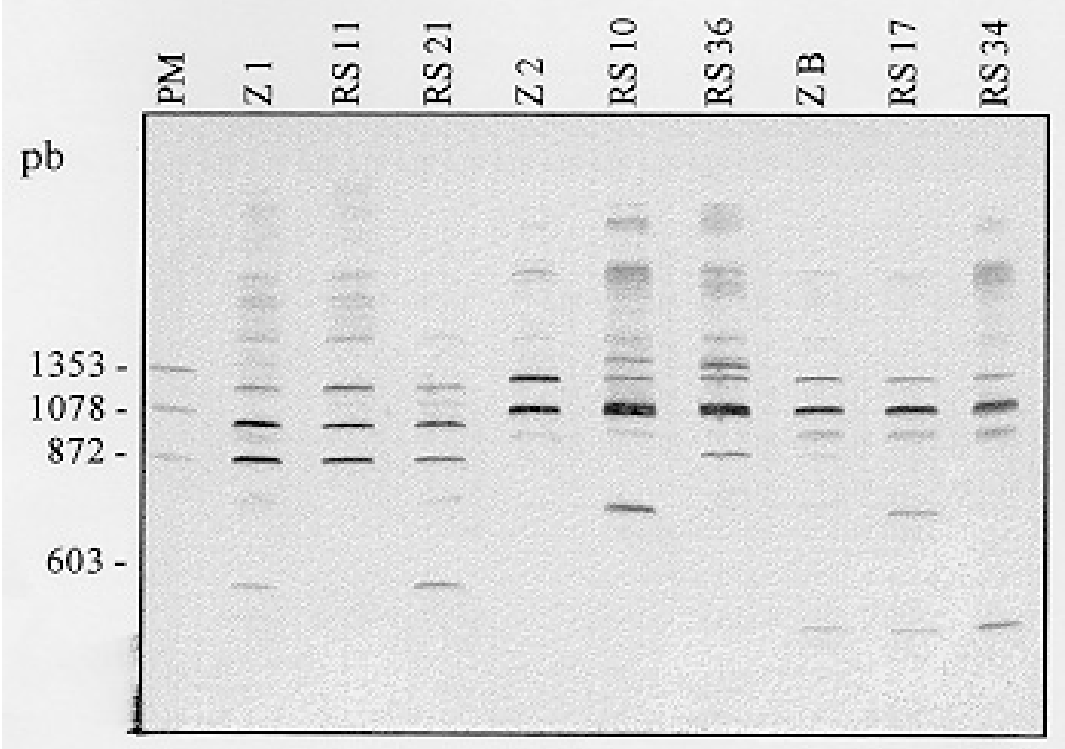

Fig. 4: a 4\% polyacrylamide gel stained with silver shows the RAPD profiles of Trypanosoma cruzi strains from the State of Rio Grande do Sul together with standard T. cruzi zymodemes amplified with primer 3303. RS11 and RS 21 (Z1), RS 10 and RS 36 (Z2), RS 17 and RS 34 (ZB) are representative zymodemes from the State of Rio Grande do Sul. Z1, Z2 and ZB are the standard T. cruzi zymodemes.

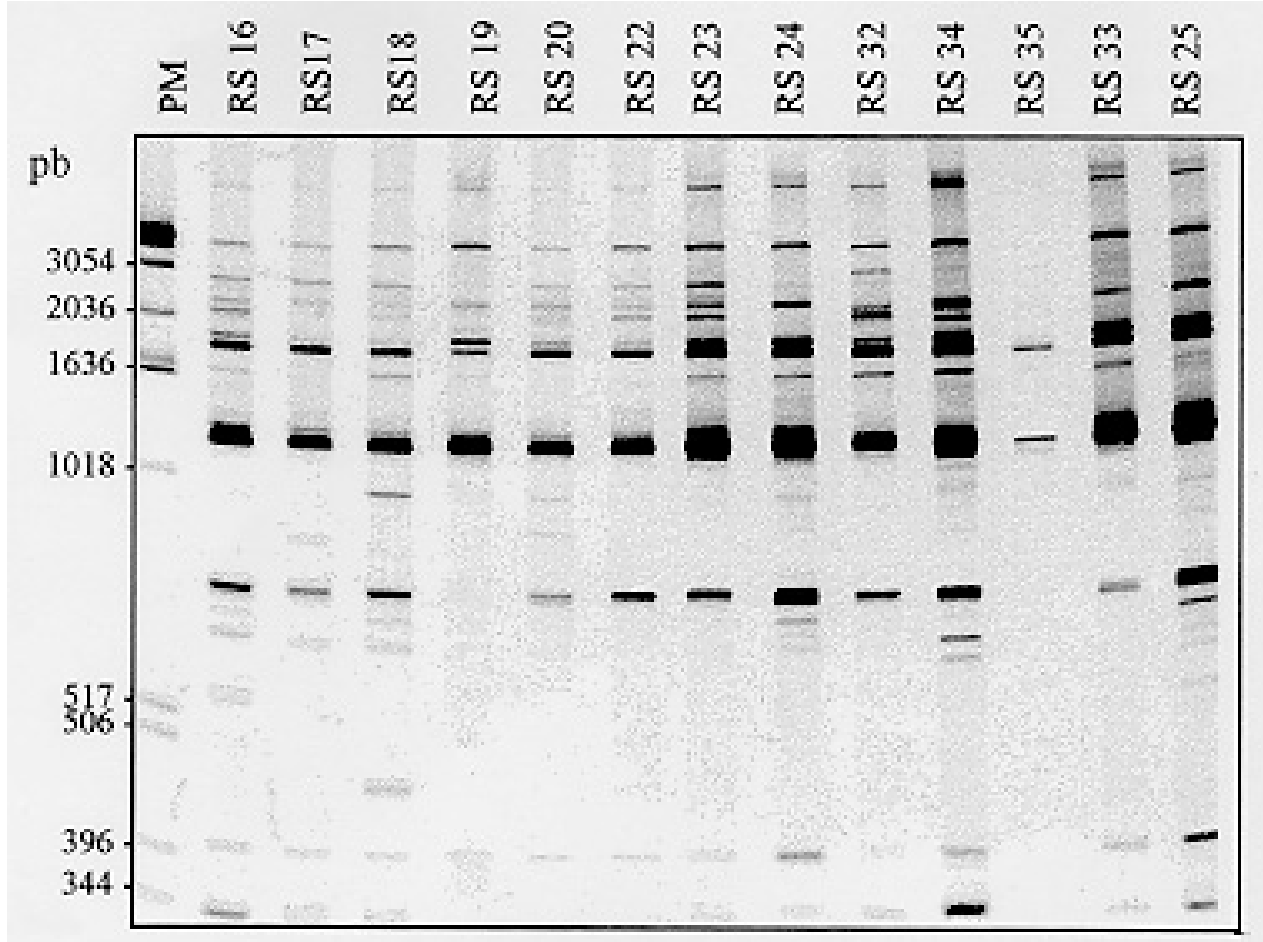

Fig. 5: a 4\% polyacrylamide gel stained with silver shows the RAPD profiles of 13 zymodeme ZB Trypanosoma cruzi strains from the State of Rio Grande do Sul amplified with primer 3307. 


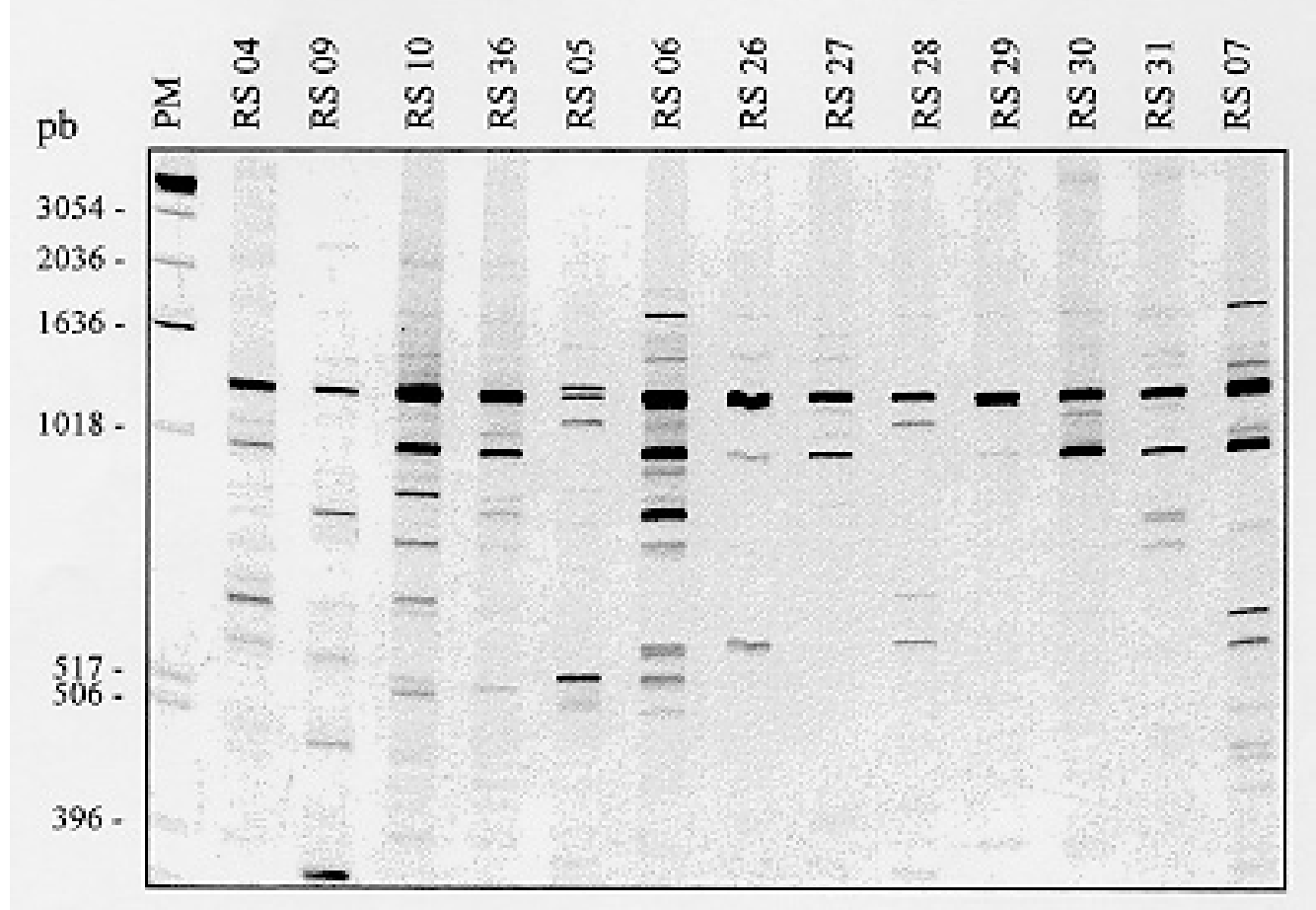

Fig. 6: a 4\% polyacrylamide gel stained with silver shows the RAPD profiles of 13 zymodeme Z2 Trypanosoma cruzi strains from the State of Rio Grande do Sul amplified with primer $\lambda$ gt11R.

3 primers (3307, $\lambda \mathrm{gt} 11 \mathrm{R}$ and $\lambda \mathrm{gt} 11 \mathrm{~F})$ were used for a comparison of the RAPD profiles of the same ZB and $\mathrm{Z} 2$ strains, the percentage of bands shared within zymodeme ZB and Z2 strains was of 19/95 (20\%) and 12/87 (14\%) respectively.

\section{DISCUSSION}

T. cruzi populations have been characterized on the basis of biological behaviour in mice (Brener 1977, Andrade 1985). Parasitemia studies in albino mice of 35 T. cruzi strains isolated from chronic chagasic patients, and naturally infected vectors ( $T$. infestans and $P$. megistus) and from opossums (D. albiventris) from Rio Grande do Sul, showed that $33(94 \%)$ of the strains were of low and $2(6 \%)$ of high virulence to mice. All 29 strains isolated from chronic chagasic patients as well as 2 strains isolated from $T$. infestans and 2 from $D$. albiventris induced similar parasitemia levels and were of low virulence to mice. On the other hand, strains (RS11 and RS21) isolated from P. megistus were highly virulent to mice. T. cruzi of high, medium and low virulence and strains that did not induce patent parasitemia in mice have been isolated from chronic chagasic patients (Schlemper Jr et al. 1983, Carneiro et al. 1991) and from sylvatic reservoirs and vectors (Steindel 1993). Our results confirm the predominance of T. cruzi strains of low virulence to mice in chronic chagasic patients.

Isoenzyme electrophoresis of 35 T. cruzi strains from Rio Grande do Sul showed the presence of 3 major zymodemes Z1, Z2 and ZB. T. cruzi Z1 was found associated with the sylvatic vector $P$. megistus, whereas $\mathrm{Z} 2$ parasites came from chronic patients and from opossums. Zymodeme ZB parasites were found in both chronic chagasic patients and in the domestic vector $T$. infestans. Our results show that in Rio Grande do Sul 2 independent transmission cycles of $T$. cruzi occur: a sylvatic cycle comprising $\mathrm{Z} 1$ parasites and the vector $P$. megistus and possibly wild mammals and a domestic cycle comprising T. cruzi $\mathrm{Z} 2$ and $\mathrm{ZB}$, the vector T. infestans and man. T. infestans is the main vector of Chagas' disease and the only domiciliated triatomine species recorded in Rio Grande do Sul (Coutinho et al. 1952). Nowadays, due to the triatomine control campaign developed by the FNS, house infestation by T. infestans is rare. On the other hand, human dwellings are sporadically invaded by adults of wide spread sylvatic triatomine species as $P$. megistus and $T$. rubrovaria. The role of these triatomine species in $T$. cruzi transmission to 
man is still unknown.

In Brazil, 6 major T. cruzi zymodemes (Z1, Z2, $\mathrm{Z3}, \mathrm{ZB}, \mathrm{ZC}$ and $\mathrm{ZD})$ have been recorded from chagasic patients (Miles et al. 1977, 1978, Romanha 1982). In the central region of Brazil, zymodeme $Z 2$ parasites are the most frequently found in chronic chagasic patients, whereas both $\mathrm{Z} 1$ and $\mathrm{Z} 2$ zymodemes were found in acute infections (Luquetti et al. 1986). T. cruzi Z2 (59.4\%) and ZB $(20.3 \%)$ were also the most frequent parasites isolated from chronic chagasic patients from Bambuí city, State of Minas Gerais (Romanha 1982). In the present work, $38 \%$ of the T. cruzi strains isolated from chagasic patients were $\mathrm{Z} 2$ and $62 \%$ were $\mathrm{ZB}$. Our results show that in Rio Grande do Sul, at least 2 distinct $T$. cruzi zymodemes infect man. Isoenzyme data of $T$. cruzi strains from human and non human origin comprising a wide geographical distribution showed that this parasite presented a clonal structure (Tibayrenc \& Ayala 1988, Ayala 1993). On the other hand k-DNA and DNA fingerprinting analyses show that a single $T$. cruzi strain may be composed by clones with different genetic characteristics (Morel et al. 1980, Macedo et al. 1992). The intrazymodeme heterogeneity found here in some $T$. cruzi strains from human and sylvatic origin suggests that different sub populations of the parasite may be present in the same host.

Opossums are the most important sylvatic reservoirs of $T$. cruzi known and play an important role in the maintenance of the sylvatic $T$. cruzi transmission cycle. Zymodeme Z1 parasites was the only zymodeme found in a large number of $T$. cruzi strains isolated from $D$. albiventris from Bambuí, Minas Gerais and from D. marsupialis from the State of Santa Catarina, respectively, endemic and non endemic areas of Chagas' disease in Brazil (Fernandes et al. 1991, Steindel 1993). In contrast, T. cruzi zymodeme $\mathrm{Z} 2$ was isolated from 2 naturally infected $D$. albiventris from Rio Grande do Sul. Since the opossums were captured in the peridomiciliar environment, they might have been infected by domestic vectors. The sinantropic behaviour of Didelphis sp., represents a relevant epidemiological role in the link of the sylvatic and domestic $T$. cruzi transmission cycles. Recently, $T$. cruzi $\mathrm{Z} 2$ were also recorded from naturally infected marsupials Philander opossum and D. marsupialis in the State of Rio de Janeiro (Pinho et al. 1994) and from $D$. albiventris from the Chaco forest in Argentina (Wisnisvesky-Colli et al. 1992).

In addition to isoenzyme, RAPD profile was also used to characterize T. cruzi from Rio Grande do Sul. The RAPD profiles generated with 4 random primers resulted in complex band patterns, and showed a high genetic heterogeneity of the $T$. cruzi populations studied. A previous extensive analysis of $T$. cruzi strains belonging to distinct zymodemes showed a close correlation between the major groups defined by RAPD and zymodemes (Steindel et al. 1993, Tibayrenc et al. 1993). We obtained similar results when T. cruzi $\mathrm{Z1}, \mathrm{Z} 2$ and ZB strains were compared using primer 3303. In the present study a comparison of the RAPD profiles of $2 \mathrm{Z} 1$ strains generated with 2 primers showed that $74 \%$ of the bands were shared. A more extensive analysis of $T$. cruzi $\mathrm{Z} 1$ from a wide geographical distribution showed that an average of 55\% of the RAPD bands were shared between the strains (Steindel et al. 1993). Using a single primer and a more limited number of strains the authors found that the percentage of bands shared within zymodeme was $73.6 \%$ for $\mathrm{Z} 2$ and $70.1 \%$ for $\mathrm{ZB}$. In the present study, where a more significant number of strains from zymodemes $\mathrm{Z} 2$ and $\mathrm{ZB}$, were compared using primers 3307 , $\lambda \mathrm{gt} 11 \mathrm{R}$ and $\lambda \mathrm{gt} 11 \mathrm{~F}$ a higher intrazymodeme genetic heterogeneity was evidenced. Using primer $\lambda \mathrm{gt} 11 \mathrm{~F}$ the percentage of RAPD bands shared within $13 \mathrm{ZB}$ and $13 \mathrm{Z} 2$ strains was respectively $43.3 \%$ and $33.3 \%$. However, when 3 primers were used, the bands shared decreased to $20 \%$ for $\mathrm{ZB}$ and $14 \%$ for $Z 2$. The heterogeneity found in our $T$. cruzi $\mathrm{ZB}$ and $\mathrm{Z} 2$ strains from chronic patients shows that these parasite populations are more polymorphic and demonstrates the analytical power of RAPD. It remains to be observed if there is a relationship between the high genetic heterogeneity of $T$. cruzi strains and different clinical forms of human Chagas' disease in Rio Grande do Sul.

\section{REFERENCES}

Andrade SG 1985. Morphological and behavioural characterization of Trypanosoma cruzi strains. Rev Soc Bras Med Trop 18 (Suppl.): 39-46.

Ayala FJ 1993. Trypanosoma and Leishmania have clonal population structures of epidemiological significance. Biol Res 26: 47-63.

Baruffa G 1987. Atualização em doença de Chagas. $R$ AMRIGS 31: 220-223.

Baruffa G, Alcântara Filho A 1977. Prevalência sorológica da doença de Chagas na zona sul do Rio Grande do Sul (Brasil). Rev Inst Med Trop São Paulo 19: 117-123.

Baruffa G, Alcântara Filho A 1985. Inquérito sorológico e entomológico da infecção pelo T. cruzi na região Sul do Rio Grande do Sul, Brasil. Ann Soc belge Med trop 65: 171-175.

Brener Z 1962. Contribuição ao estudo da terapêutica experimental da doença de Chagas. Thesis, Universidade Federal de Minas Gerais, 77pp.

Brener Z 1977. Intraspecific variations in Trypanosoma cruzi: two types of parasite populations presenting distinct characteristics. PAHO Sci Publ 347: 11-21.

Bronfen E, Rocha FSA, Machado GBN, Perillo MM, Romanha AJ, Chiari E 1989. Isolamento de amostras 
de Trypanosoma cruzi por xenodiagnóstico e hemocultura de pacientes na fase crônica da doença de Chagas. Mem Inst Oswaldo Cruz 84: 237-240.

Carneiro M, Chiari E, Gonçalves AM, da Silva Pereira AA, Morel CM, Romanha AJ 1990. Changes in the isoenzyme and kinetoplast DNA patterns of Trypanosoma cruzi strains induced by maintenance in mice. Acta Tropica 47: 35-45.

Carneiro M, Romanha AJ, Chiari E 1991. Biological characterization of Trypanosoma cruzi strains from different zymodemes and schizodemes. Mem Inst Oswaldo Cruz 86: 387-393.

Coutinho PP, Pinto OS, Barbosa JA 1952. Contribuição ao conhecimento da distribuição dos triatomíneos domiciliários e seus índices de infecção pelo Schizotrypanum cruzi no Estado do Rio Grande do Sul, Brasil. Rev Bras Malariol Doenças Tropicais 4: 211226.

Dias JCP 1987. Control of Chagas' disease in Brazil. Parasitol Today 3: 336-341.

Dirie MF, Murphy NB, Gardiner PR 1993. DNA fingerprinting of Trypanosoma vivax isolates rapidly identifies intraspecific relationships. J Euk Microbiol 40: 132-134.

Fernandes AJ, Chiari E, Ribeiro-Rodrigues R, Dias JCP, Romanha AJ 1991. The importance of the opossum (Didelphis albiventris) as a reservoir for Trypanosoma cruzi in Bambuí, Minas Gerais State. Mem Inst Oswaldo Cruz 86: 81-85.

Luquetti AD, Miles MA, Rassi A, Rezende JM, Souza AA, Povoa MM, Rodrigues I 1986. Trypanosoma cruzi: zymodemes associated with acute and chronic Chagas' disease in Central Brazil. Trans $R$ Soc Trop Med Hyg 80: 462-470.

Macedo AM, Martins MS, Chiari E, Pena SDJ 1992. DNA fingerprinting of Trypanosoma cruzi: a new tool for characterization of strains and clones. $\mathrm{Mol}$ Biochem Parasitol 55: 147-154.

Miles MA, Souza AA, Povoa MM, Shaw JJ, Lainson R, Toyé PJ 1978. Isozymic heterogeneity of Trypanosoma cruzi in the first authocthonous patients with Chagas' disease in Amazonian Brazil. Nature 272: 819-821.

Miles MA, Toyé PJ, Oswald SC, Godfrey DG 1977. The identification by isoenzyme patterns of two distinct strains groups of Trypanosoma cruzi, circulating independently in a rural area of Brazil. Trans $R$ Soc Trop Med Hyg 71: 217-225.

Morel CM, Chiari E, Camargo EP, Mattei DM, Romanha AJ, Simpson L 1980. Strains and clones of Trypanosoma cruzi can be characterized by pattern of re- striction endonuclease products of kinetoplast DNA minicircles. Proc Natl Acad Sci USA 77: 6810-6814.

Pinho AP, Ribeiro LL, Marchewsky R, Legey AP, Jansen AM 1994. Trypanosoma cruzi in marsupials: Follow up of experimental and natural infections and characterization of the isolates that circulates between Didelphis marsupialis and Philander opossum. Mem Inst Oswaldo Cruz 89 (Suppl. I): 56.

Romanha AJ 1982. Heterogenidade enzimática em Trypanosoma cruzi. Thesis, Universidade Federal de Minas Gerais, 110 pp.

Santos FR, Pena SDJ, Epplen JT 1993. Genetic and population study of an Y-linked tetranucleotide repeat DNA polymorphism. Hum Genet 90: 655-656.

Souto RP, Fernandes O, Macedo AM, Campbell DA, Zingales B 1996. DNA markers define two major phylogenetic lineages of Trypanosoma cruzi. Mol Biochem Parasitol 83: 141-152.

Schlemper Jr BR, Ávila CM, Coura JR, Brener Z 1983. Course of infection and histopathological lesions in mice infected with seventeen Trypanosoma cruzi strains isolated from chronic patients. Rev Soc Bras Med Trop 16: 196-201.

Steindel M 1993. Caracterização de cepas de Trypanosoma cruzi e Trypanosoma rangeli isoladas de reservatórios e vetores silvestres naturalmente infectados de Santa Catarina. Thesis, Universidade Federal de Minas Gerais, 166 pp.

Steindel M, Dias Neto E, Menezes CLP, Romanha JA, Simpson AJG 1993. Random amplified polymorphic DNA analysis of Trypanosoma cruzi strains. Mol Biochem Parasitol 60: 71-80.

Tibayrenc M, Ayala FJ 1988. Isozyme variability in Trypanosoma cruzi, the agent of Chagas' disease: genetical, taxonomical, and epidemiological significance. Evolution 42: 277-292.

Tibayrenc M, Neubauer K, Barnabé C, Guerrini F, Skarecky D, Ayala F 1993. Genetic characterization of six parasitic protozoa: Parity between randomprimer DNA typing and multilocus enzyme electrophoresis. Proc Natl Acad Sci USA 90: 1335-1339.

WHO 1991. Control of Chagas disease. Report a WHO Expert Commitee. Geneva. WHO Technical Report Series 95: 811.

Wisnivesky-Colli C, Schweigmann NJ, Alberti A, Pietrokovsky SM, Conti O, Montoya S, Riarte A, Rivas C 1992. Sylvatic American trypanosomiasis in Argentina: Trypanosoma cruzi infection in mammals from the Chaco forest in Santiago del Estero. Trans $R$ Soc Trop Med Hyg 86: 38-41. 
352 Characterization of Trypanosoma cruzi Strains - CD Fernandes et al. 